\title{
Linking fluid dynamics and olivine crystal scale zoning during simulated magma intrusion
}

\author{
Lilu Cheng $^{1} \cdot$ Fidel Costa $^{1,2} \cdot$ George Bergantz $^{3}$
}

Received: 2 October 2019 / Accepted: 21 April 2020 / Published online: 6 May 2020

(c) The Author(s) 2020

\begin{abstract}
The compositional zoning styles of natural crystals produced during magma intrusion can be used to investigate the structure of magmatic plumbing systems and its relation to expressions of volcanic unrest (seismic, deformation, volatiles). However, magma intrusion is a progressive, dynamic process and yields non-monotonic heterogeneities in physio-chemical variables such as complex spatial variations in temperature and liquid composition with time. Such changes in variables are difficult to incorporate in models of crystal zoning in natural systems. Here we take another approach by integrating the results of a numerical multiphase simulation of melt arrival in an olivine-rich reservoir with models of chemical re-equilibration of olivine. We evaluate the diversity of chemical zoning styles and the inferred time scales using $\mathrm{Fe}-\mathrm{Mg}$ diffusion in olivine for a limited range of system geometries and time-composition-temperature values. Although our models are still a large simplification of the processes that may occur in natural systems we find several time-dependent and systematic relations between variables that can be used to better interpret natural data. The proportions of zoned and unzoned crystals, the zoning length scales, and the calculated diffusion times from the crystals, vary with time and the initial position of the crystal in the reservoir. These relationships can be used, for example, to better constrain the plumbing structure and dynamics of mafic eruptions from monogenetic volcanoes by detailed studies of changes in the zoning of the crystal cargo with eruptive sequence. Moreover, we also find that the time scales obtained from modeling of crystals at a single temperature and boundary condition tend to be shorter ( $>$ about $25 \%$ ) than the residence time, which could also be tested in natural studies by combining crystal time scale records with monitoring datasets.
\end{abstract}

Keywords Olivine $\cdot$ Modeling $\cdot$ Timescale $\cdot$ Crystal zoning $\cdot$ Eruption

Communicated by Othmar Müntener.

Electronic supplementary material The online version of this article (https://doi.org/10.1007/s00410-020-01691-3) contains supplementary material, which is available to authorized users.

Lilu Cheng

1lcheng@ntu.edu.sg

1 Earth Observatory of Singapore, Nanyang Technological University, 50 Nanyang Ave, Singapore 639798, Singapore

2 Asian School of the Environment, Nanyang Technological University, 50 Nanyang Av, Singapore 639798, Singapore

3 Department of Earth and Space Sciences, University of Washington, Seattle 98195, USA

\section{Introduction}

Modeling the zoning patterns of crystals can provide insights into the processes time scales and processes that occur below volcanoes (e.g. Costa et al. 2008, 2020; Morgan and Blake 2006; Turner and Costa 2007; Costa and Morgan 2011). This crystal-scale information can be used to unravel the architecture and processes of volcano plumbing system, and can be combined with time series of volcano monitoring (seismic, deformation, gas) or other observational data (e.g., ash emissions) to illuminate causative relations that allow to better anticipate eruptions (Albert et al. 2015, 2019; Kahl et al. 2017; Morgan et al. 2006; Rasmussen et al. 2018; Ruth et al. 2018; Saunders et al. 2012; Kilgour et al. 2014; Rae et al. 2016; Tomiya et al. 2013). For example, time correlations between changes in seismicity or gas and those of crystal zoning can be interpreted as diagnostic for new magma intrusions (e.g. Kahl et al. 2011; Pankhurst et al. 
2018). However, magmatic systems and the crystal cargo are heterogeneous at a variety of scales, and magma additions into pre-existing reservoirs likely involves a wide range of physical and chemical changes that are difficult to uniquely account for in models of crystal zoning (Bergantz et al. 2015; Cheng et al. 2017; Costa et al. 2010; Macdonald et al. 2008; Nakamura 1995; Probst et al. 2018; Wallace and Bergantz 2005). Although it is possible to construct relatively sophisticated models of compositional changes at the boundary of crystal and temperature with time (e.g. Costa et al. 2008; de Maisonneuve et al. 2016), it is unclear how to extend that to the complexities of natural events.

Modeling of crystal-fluid interactions is not straightforward, as the presence of crystals greatly affects the mechanics of a magma even at crystal concentrations of as little as 25 vol. \%, as the system can form crystal-contact networks (Philpotts et al. 1999), yielding fragile networks by the transmission of stress by crystal-crystal contacts called force chains (Bergantz et al. 2017; Sun et al. 2010; Sandnes et al. 2011; Estep and Dufek 2012). Thus, simple suspension rheology is inadequate to resolve crystal transport and reaction at the crystal scale. Investigating the mechanics involved in an open-system intrusion requires an approach that resolves both the micro (crystal-scale) physical interactions and the meso-scale circulation. Bergantz et al. (2015) used a discrete element method-computational fluid dynamics approach that includes crystal-scale frictional, collisional, translational, and buoyant forces, as well as viscous particle-fluid coupling under basaltic conditions. The particle-based simulation records the physical interactions and circulation of all crystals and creates a times series for each individual crystal as a record of changes in temperature and composition. Linking the results of such fluid-dynamic simulations with the processes of chemical re-equilibration within the crystal allow us to test the effects of changing boundary and temperature conditions into the time scales that are obtained from natural crystals (Schleicher and Bergantz et al. 2017).

An obstacle in the application of crystal zoning studies to magmatic systems is that sample sizes are very small relative to total crystal contents, and sampling itself can be very incomplete. There is a need for an interpretive framework that will move the sparse crystal chemical data to the mesoto-macro scale. Hence the goal of this work is to be a proofof-concept for an approach that combines an intentionally simplified simulation of an open-system event with measures of zoning that are widely applied to complex natural systems. The objective is not to produce a highly resolved simulation of a specific natural system, but instead to explore how the most important degrees of freedom present in a generic, simple system may produce and inform the observed diversity in a naturally occurring crystal cargo. A related objective is to illuminate the statistics of establishing ergodicity in any study that employs crystal zoning. Each magmatic system is the result of a unique process of construction and open-system events, differing intensive variables and local kinetics. Hence we focused on, and demonstrated various measures in, the crystal cargo related to the system-wide behavior and global concepts at the meso-to-macro scale in the crystal cargo, which can't be otherwise attainable under current sampling protocols. Our intention is not to provide a detailed description of a particular geological episode but instead demonstrate various statistical approaches that are needful in the development of an interpretive framework.

Here we focus on the interaction and reequilibration of olivine in basaltic melts and Illustrate should be illustrate the relationships between the time scales of the different processes, the effects on crystal zoning patterns, and show how these can be recognized and accounted for by large numbers of crystals to create an ergodic population and down-sampling strategy. We also discuss the potential use of our results for the interpretation of natural crystals in basaltic eruption sequences and the monitoring signals that precede them.

\section{Methods: fluid dynamic simulations and crystal scale modeling}

\section{Numerical simulations of magma intrusion in reservoir}

Bergantz and collaborators (Bergantz et al. 2015, 2017; Carrara et al. 2019; Schleicher and Bergantz 2017; Schleicher et al. 2016) have used a discrete element method to perform computational fluid dynamic models of a crystal-free basaltic liquid intruding at the base of a crystal-rich mush of olivine. In their simulation magma is intruded from below and through a crystal-rich pile. They found that most magma interactions occurred within the so-called "mixing bowl", which is a wedge-shaped area of the crystal mush right above where the intrusion occurs. The geometry of the mixing bowl is set by the failure along initially frictional contacts of the settled crystals, producing what is known as melt-present faults, widely observed in the plutonic environment (e.g. Bergantz et al. 2015). As most of the circulation is within the mixing bowl, this is where thermo-chemical effects of melt on the crystals will be maximal. The simulations incorporate a range of realistic parameters for the fluid and crystal dynamics (details in Appendix of Bergantz et al. (2015; 2017)) and track the position and a parametrized boundary temperature of hundreds of thousands of crystals. A first order finding of these simulations is that crystals may experience a wide range of environments over time and thus a wide range of crystal zoning patterns can be produced even during a single open-system event.

Here we use the results from Schleicher and Bergantz (2017) to evaluate the importance of the changes in environment that individual crystals may experience during a 
situation that tries to simulate magma mixing/mingling. We use these results to make some inferences and relate them to studies of natural crystals. The numerical simulations of Schleicher and Bergantz (2017) used the following range of physical and chemical parameters: a domain size of about $2.6 \times 1.3 \mathrm{~m}$, an initial thickness of the crystal pile of $0.8 \mathrm{~m}$ $\left(=H_{o}\right)$, and a olivine crystal diameter of $4 \mathrm{~mm}$, there was only one crystal size in these simulations. The Reynolds number $\left[\left(=\operatorname{Re}=\left(U_{o} \times d \times \rho_{\mathrm{f}}\right) \mu_{f}\right.\right.$, where $U_{o}$ is the magma input velocity, $d$ is the length scale of the entrance of magma input, $\rho_{\mathrm{f}}$ and $\mu_{\mathrm{f}}$, are the fluid density and viscosity, respectively)] varies between about 0.1 and 1 . The composition and temperature of the melt was parameterized with a scalar whose value was equal to zero for the resident melt, and one for the intruding melt, with values in between reflecting mixing proportions between resident and new intruding melt. The time $(t)$ of the simulations was $100 \mathrm{~s}$ but was normalized with $t^{*}=\left(\mathrm{U}_{\mathrm{o}} / \mathrm{H}_{\mathrm{o}}\right) \times t$, where $U_{\mathrm{o}}$ is as above, and $H_{\mathrm{o}}$ is the vertical thickness of the crystal mush. The simulations were run for $t^{*}$ values of $0-2.75$.

To combine the results of these simulations with the olivine zoning patterns modeled here time needs to be rescaled: the $100 \mathrm{~s}$ that were simulated are not representative of the times that are typically recorded from olivine zoning in basaltic magmas, which range from a few days to a few months (e.g. Albert et al. 2016; Lynn et al. 2017; Ruth et al. 2018; Pankhurst et al. 2018). Thus, we chose a time of 0-100 days as the residence time (Fig. 1) that is representative of those from natural crystals, and we focus on the changes of the system at 10, 40, 70 and 100 days. We note that in the fluid dynamic simulations the intrusion begins at $t=0$ and continues for 60 days, and then stops. This means that the duration of the intrusion is relatively long compared to the longest time residence time of 100 days. To conserve the $t^{*}$ of the simulations requires increasing the thickness of the initial crystal pile by about $\times 1000$ (so instead of about $0.8 \mathrm{~m}$ it would be $800 \mathrm{~m}$ ), and decreasing the input magma velocity by $\times 100$. Such changes would increase the Reynolds number by $\times 10$, but this can be compensated by an increase of the width of the incoming magma by the same amount (see Online supplementary Appendix 1 and Table 1s). Thus, although our total times are quite different from those of the fluid dynamics simulations, the scaling of the system to larger sizes still preserves the main relations of the simulations and thus are still a good proxy for the dynamics during melt and crystal interactions.

For the models of olivine re-equilibration, we tracked the changes of the crystal position and local scalar value at the boundary of all the 23,822 crystals from the "mixing bowl". Thus, all the active crystals are sampled so it is a perfectly ergodic sample of the process. We used the scalar value as a proxy for the temperature $(T)$ that the crystal experienced over time. The initial condition is a scalar value of zero corresponding to $T=1150{ }^{\circ} \mathrm{C}$ and is uniform throughout the crystal pile, and a value of one corresponds to $T=1200{ }^{\circ} \mathrm{C}$, which is that of the intruding magma. Mixing of resident and new melt was quantified by a linear relation between the scalar and temperature values. We used a basaltic andesite composition and MELTS (Ghiorso and Sack 1995) to derive a relation between the forsterite content (Fo as chemical indicator of the Fe/Mg) and the temperature (detailed in Online supplementary Appendix 1; the same as used in Costa et al. (2008)):

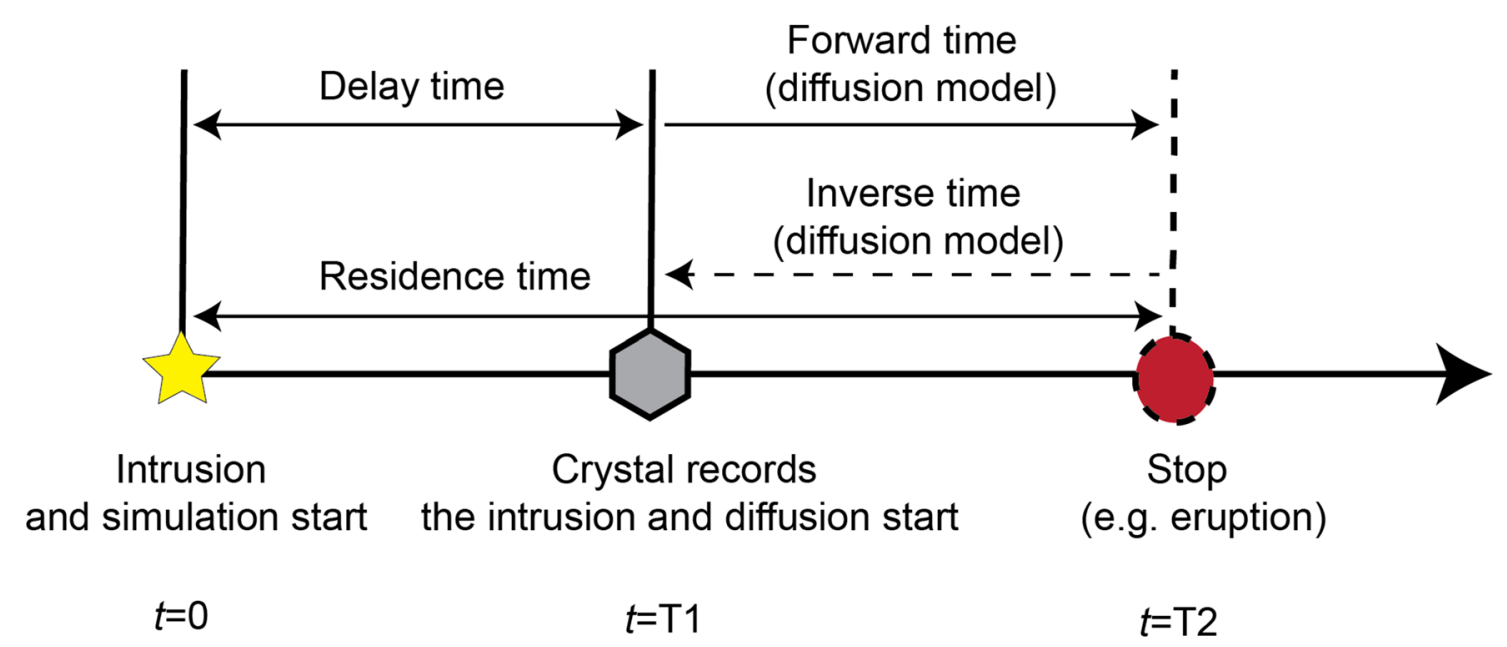

Fig. 1 Illustration of the different time scales we employed in this study. Delay time is the time interval between when the start of the intrusion and when the crystal first records it as a change at the boundary. This interval varies from crystal to crystal as they stay in different parts of magma reservoir. We call forward time that which is obtained from diffusion models that use the boundary and temperature evolution of the fluid-dynamic simulations. We also calculate an inverse time from the crystal zoning via diffusion models as if they were natural crystals. Finally, the total time from intrusion start to eruption is the residence time 
$F o=\left(-0.0013417 \cdot T^{2}+3.3111 \cdot T-1959.1\right) / 100$,

where, $T$ ranges from 1150 to $1200^{\circ} \mathrm{C}$, at an oxygen fugacity buffered at the $\mathrm{N}-\mathrm{NiO}$ reaction and 1 bar. The resident magma was thus made of olivine crystals that were unzoned and of $F_{\mathrm{O}}=0.74$ throughout. The intruding magma had the same basaltic composition but was at $1200{ }^{\circ} \mathrm{C}$ and is crystal free, but would be in equilibrium with about $F_{\mathrm{O}}=0.82$.

\section{Modeling of olivine reaction progress and chemical zoning}

For the re-equilibration of olivine we considered that the compositions of the crystals were modified only by diffusion from the rim towards the interior, and thus the driving forces for the chemical zoning were the changes of melt and temperature at the boundary with time. Schleicher and Bergantz (2017) used a parametrized solution for the convective crystal dissolution (Zhang 2008) and obtained very high dissolution rates that would basically dissolve all the crystal in the mush within several hours. However, the parametrized model is valid for an infinite melt with a constant composition, and thus yields higher dissolution rates than for the case of a crystal mush with a liquid composition that is changing with time due to dissolution, growth, and diffusion. Several analytical solutions exist for dissolution and crystal growth on the convective regime (e.g. Zhang 2008), but these are also for semi-infinite liquid condition. Currently there is no widely accepted model or parameterizations to properly couple the effects of magma dynamics with crystal growth and dissolution. Thus, in addition to a simplified magma chamber our model calculations also simplify the details of the crystal-melt boundary interactions, as crystal growth, dissolution, and diffusion are occurring concurrently, and these processes will have an effect on the temperature, liquid compositions, and thus the details of the crystal and liquid dynamics. However, studies of natural olivine crystals can typically distinguish between the effect of crystal growth and diffusion, and quite a few of them have shown that the $\mathrm{Fe}-\mathrm{Mg}$ zoning of the olivine can be better explained by diffusion (using arguments of diffusion anisotropy and modeling of multiple elements; e.g. Costa and Dungan (2005); Costa et al. (2008); Kahl et al. (2015); Shea et al. (2015)) than by crystal growth. Despite the limited range of parameter values that we have been able to explore, and the simplification of the processes at the crystal-melt boundary, our approach is more sophisticated than previous models as it captures the complexities of changing boundary conditions with time and the effects it may have in crystal zoning that is dominated by diffusion.

For modeling the zoning patterns, we used Fick's second law of diffusion and the diffusion coefficient of $F_{\mathrm{O}}$ $\left(D_{F o}\right)$ including compositional dependence and the relation from (Dohmen and Chakraborty, 2007a; Dohmen and Chakraborty, 2007b) parallel to $c$ axis (in $\mu \mathrm{m}^{2} \mathrm{~s}^{-1}$ ):

$$
\begin{aligned}
D_{F o}= & \left(D_{0} \cdot\left(\left(\frac{f o_{2}}{10^{12}}\right)^{\frac{1}{6}}\right) \cdot 10^{3(0.9-F o)}\right. \\
& \left.\cdot \exp \left(\frac{-E}{8.31 \times 10^{-3} \times(T+273)}\right)\right) \cdot 10^{12}
\end{aligned}
$$

With $f \mathrm{O}_{2}$ at the Ni-NiO buffer, $D_{\mathrm{o}}=6.17 \times 10^{-10}, E=201$ $\mathrm{kJmol}^{-1}, T$ in ${ }^{\circ} \mathrm{C}$. We performed two types of modeling: (1) diffusion in the crystal using the temperature and boundary composition changes with time as indicated by the fluid dynamic simulations, which give us the "forward time" (Fig. 1), and (2) diffusion models of the same profiles as one would do if they were natural crystals, which we call "inverse time" (Fig. 1). In these models the temperature and boundary evolution with time are unknown, and we used two approaches as a proxy for the temperature: (2a) using a mean temperature of $1175^{\circ} \mathrm{C}$ for all crystals, and (2b) using the maximum Fo measured as a proxy for temperature so that each crystal may be modelled at a different temperature according to its profile. For the initial profiles in both cases we either used a homogenous composition throughout the profile for simple reverse profiles, or step-wise changes in Fo for complexly zoned crystals. These are standard conditions used in many studies (e.g. Costa et al. 2008). In addition to the forward and inverse times, we use the term "residence time" to indicate the time since the beginning of melt intrusion and the quenching of the system (e.g. due to eruption), and the "delay time" is the time since the beginning of intrusion and the moment that the crystals first record a change at their rim (Fig. 1). In the models we tracked the compositional changes and calculated the diffusion profiles and times for 23,822 crystals. The models were run in the supercomputer cluster (Komodo) of Nanyang Technological University with a total of 70 nodes installed with Centos 6.5 OS. The nodes have 24 cores intel processors (Intel(R) Xeon(R) CPU E5-2609 0 @ 2.40 GHz) and 128 GB memory each.

\section{Results}

Our model of the coupling of the fluid dynamic simulations with diffusion in the crystal emphasizes two main controls on the nature of the crystal cargo. One is that there is a time delay between the beginning that new liquid enters the reservoir and the time the crystal rims record it, and this delay changes with time and space, and should also be dependent on the duration of the intrusion. The other is that crystal rims can experience multiple compositional changes at their margins over time, and thus 
the observed zoning after quenching does not necessarily reflect the complex history of the crystal. While both of these are to be expected, here we show how their impacts can be independently quantified. To link the simulations and diffusion modeling to applications for natural crystals, we calculate the forward and inverse times from the crystal zoning, and we evaluate their different times using two different temperature proxies and zoning styles. The different topics of the results are presented in sequence below.

\section{Delay between the beginning of intrusion and when the crystals first start recording it}

One explicit result of the numerical simulations of magma intrusion by (Bergantz et al. 2015; Schleicher and Bergantz. 2017) is that different crystals encounter the new melt (as changes in the boundary composition) at different times. This means that there is a delay between the time of the beginning of the intrusion and the moment each crystal records it with a change at the boundary which we call delay time. We tracked the position and changes at the boundary of the 23,822 crystals from different positions in the 'mixing bowl' and calculated the time delay since the beginning of the intrusion, and how the response with the residence time (Fig. 2). We find that the magnitude of the delay depends on the residence time. For example, after a residence time of 10 days, most crystals (about 80\%) have not yet recorded the intrusion (Fig. 2), meaning that if we were to quench the system (e.g. during an eruption) $80 \%$ crystals would show no zoning. For a longer residence time of 40 days, many more crystals have started to record the intrusion, but there still is about $15 \%$ of them which have not (Fig. 2). After more than about 70 days of residence all crystals have recorded at least one change at a boundary (Fig. 2). However, the delay time varies depending on the original location of the crystal when the intrusion first started: crystals proximal to the new intrusion (from the bottom of the mixing bowl in this case) show less delay than those at further away (at the top of the mixing bowl); this can be expected as the simulations we used are for a melt intrusion from the bottom of the crystal pile. Moreover, the delay probably also depends on the duration of the intrusion.

Such delays in changes at the boundary imply that the crystals would only start diffusing significantly after the first intrusion event, and thus they will record shorter times than the real intrusion time. It also implies that quenching of the system at a given time could yield a significant number of unzoned crystals. These findings are of general value and applies for different configurations of melt intrusion and to models that incorporate growth or dissolution, because the

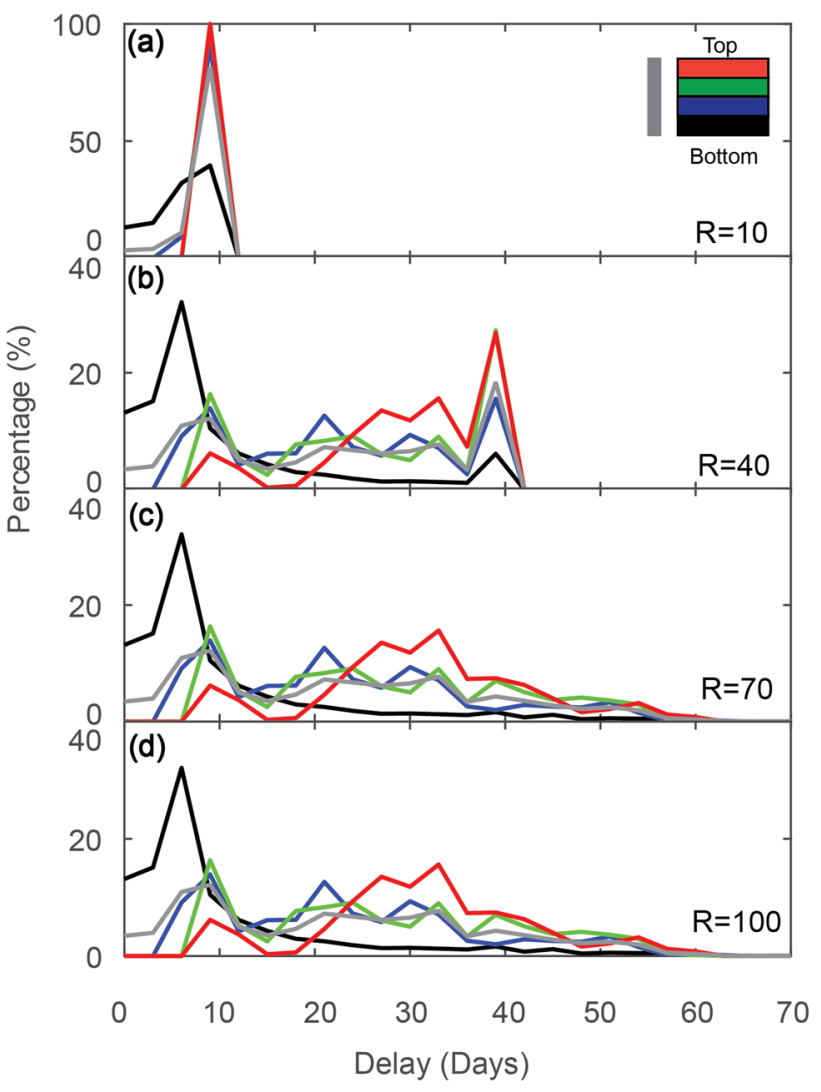

Fig. 2 Delay time (=time since crystal first records a change in the boundary minus intrusion time) distribution for different residence times $(R=10,40,70$ and 100 days) and different locations of the crystals in the mixing bowl as shown in colors according to the box shown in panel (a). Grey color curve is the mean for all the crystals in the mixing bowl, the curves in other colors range from black for crystals located at the bottom $(=25 \%$ lower part of the mixing bowl) to red for crystals at the top $(=25 \%$ of the upper part of the mixing bowl)

crystals will only start reacting once their environment has been perturbed.

\section{Olivine zoning patterns}

The coupled modeling of fluid dynamic simulations and diffusion of Fo in olivine crystals produces a significant variety of zoning patterns (Fig. 3). Most crystals have simple reverse zoning patterns, with a higher and variable Fo at their rims $\left(\mathrm{Fo}_{75}\right.$ to about $\left.\mathrm{Fo}_{82}\right)$ than at their interiors. Others are more complexly zoned, with a reverse intermediate zone of higher $\mathrm{Fo}\left(\mathrm{Fo}_{75}\right.$ to $\left.\mathrm{Fo}_{77}\right)$ than their interiors, before they are normally zoned with lower Fo at their rims. The crystals that have not recorded the intrusion will not be zoned, and thus have homogenous Fo profiles (so-called unzoned patterns).

As the residence time increases the proportion of zoned crystals increases, from about $22 \%$ after 10 days, to about $83 \%$ after 40 days (Fig. 3), and the Fo profiles are longer and 

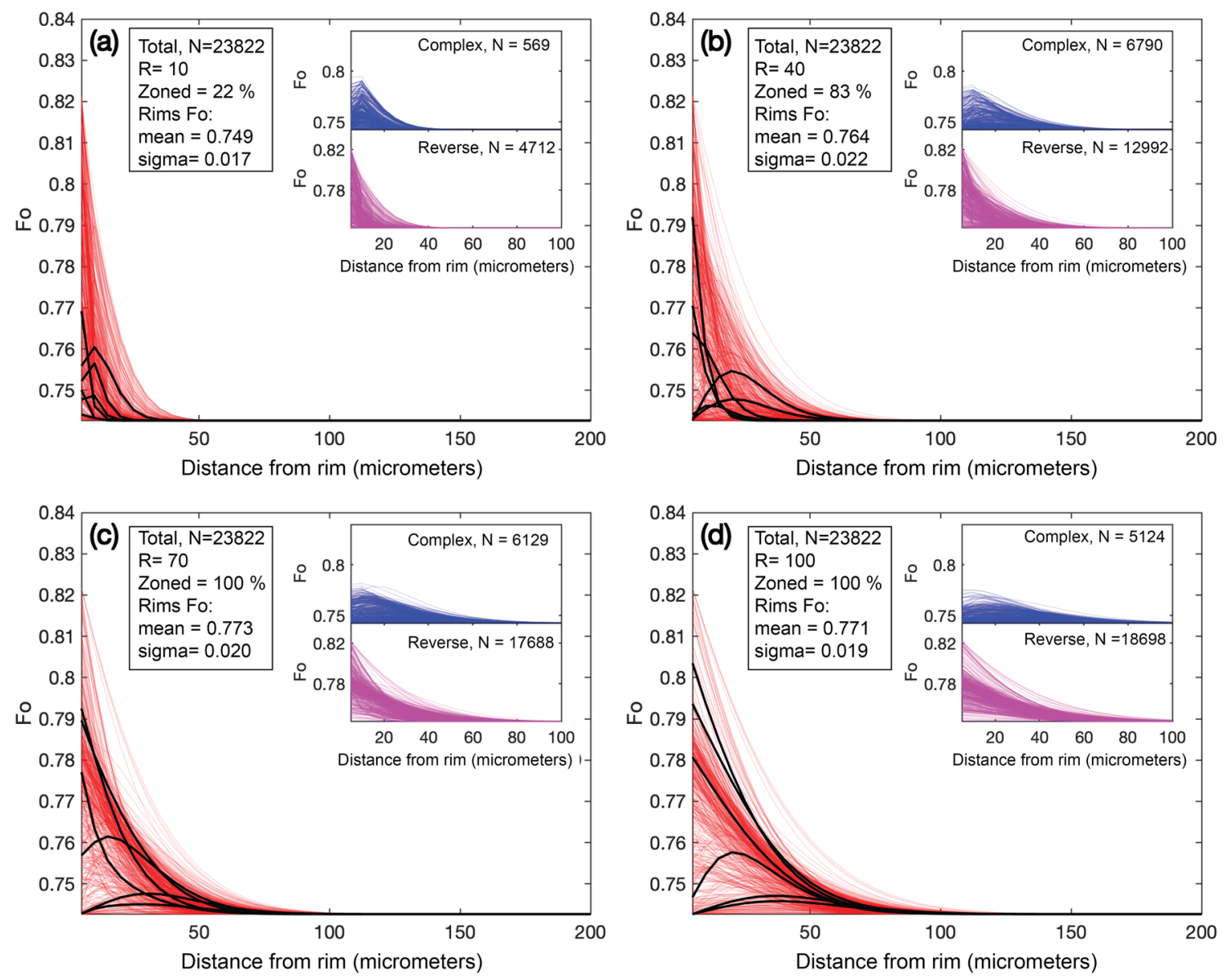

Fig. 3 Examples of 500 olivine Fo zoning profiles randomly extracted (using the "randi" function of Matlab) from the 23,822 crystals that we modelled by the coupling of the fluid dynamic simulations and diffusion for different residence times (R). Profiles in black are just some chosen illustrative examples. Inset in each panel separates the "simple" reverse zoning from the "complex" zoning patterns. The mean Fo and standard deviation (Std) of the rim compositions are reported in each panel. (a) when the residence time is 10 days only about $22 \%$ of crystals are zoned, (b) zoning Fo patterns of olivine at

40 days of residence time. The number of unzoned crystals decreases and the length of the diffusion profiles increases. (c) zoning patterns of olivine at 70 days shows that all crystals are zoned (d) zoning patterns of olivine at 100 days are similar to those at 70 days, but there appears to be a higher proportion of simple vs complex zoned crystals. We note that these are time integrated profiles but that the crystal may have experienced a wide range of compositions at the boundary over time as shown in the animation in the Online supplementary Appendix 2

smoother as crystals have more time to reequilibrate. After about 70 days all crystals are zoned, and about $70-80 \%$ of them show simple reverse zoning patterns. Moreover, the compositional variability (mean and standard deviation) of the crystal rims change over time (Fig. 3). This may reflect the progressive mixing of the liquids, although it is difficult to interpret in detail for natural systems because we can't account uniquely for crystal growth, dissolution, or the changes in the liquid composition due to diffusion with the crystals.

Although the simple zoning patterns of some crystals may lead to the inference that the conditions at their margins have been relatively constant over time, this is actually not the case, and they may have undergone several compositional reversals at their rims before the last one that produced the

normal zoning (see animation of boundary layer changes over time in Online supplementary Appendix 2). Complexly zoned crystals have also recorded a range of compositions over time and this is more completely expressed in the profiles, although still underestimates the variety of changes they have actually undergone. The types of zoning patterns we simulated are also found in basaltic andesitic rocks from magmas that have undergone mafic replenishment such as the Llaima (Chile) and Etna (Italy) volcanoes (e.g. Kahl et al. 2015; Ruth et al. 2018).

The crystal zoning profiles of Fo we simulated have an associated forward time that is significantly shorter than the residence times (Fig. 4). This difference is mainly because different crystals feel the intrusion at different times. The relative error of the forward times $(=100 \times$ forward time/ 


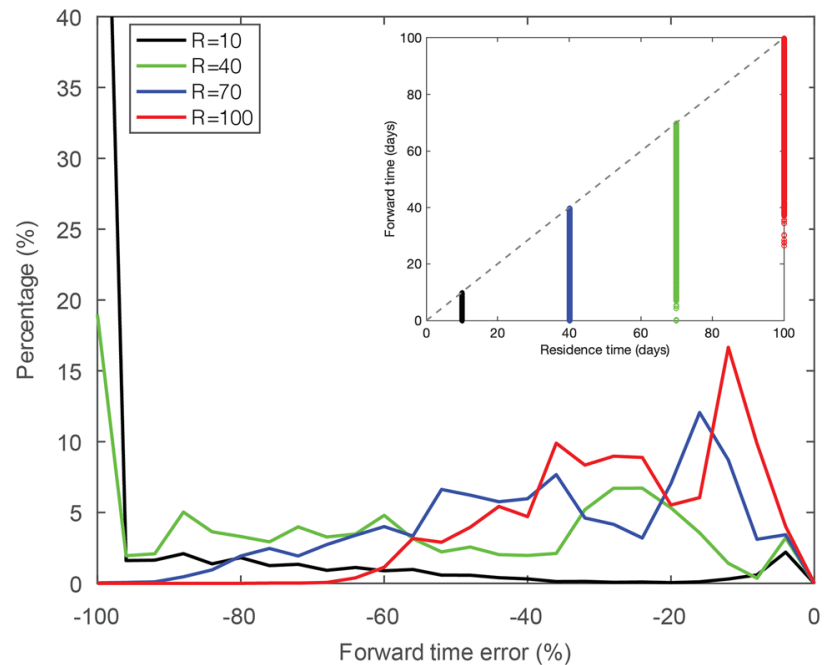

Fig. 4 Comparison of forward times and residence times. Because of the delay of the crystals experiencing the arrival of the beginning of the intrusion the forward times are shorter than the residence times (inset). This translates to relative errors of the forward time $(=100 \times$ forward time/[forward time - residence time] $)$ that are very large for short residence time (e.g. black line for residence time of 10 days) but decrease with residence time (e.g. red line for residence time of 100 days)

[forward time - residence time]) is close to $100 \%$ for most crystals (about $80 \%$ ) for a short residence time of 10 days, but as the residence time increases the error of forward times decreases, with about $50 \%$ of crystals having an error of $<30 \%$ for a residence time of 100 days. However, the spread of calculated forward times for a given residence time may also be influenced by the total duration of the intrusion.

\section{Forward and inverse models, and proxies for the temperature history to calculate inverse times from crystal zoning}

Another aspect that is important to address are the time scales that can be obtained from modeling the crystals if we did not have a priori knowledge of their temperature and boundary compositions changes. This is the common situation for most studies of natural systems, and we call these inverse times (Fig. 1; see Methods section). We obtained this from modeling the profiles produced by coupling the simulations and diffusion in the crystal shown in the previous sections but with a constant temperature and boundary composition. The temperature history is very important, as diffusion rates and thus calculated times are very temperature dependent (e.g. Costa et al. 2008). For systems that oscillate around a mean, it is possible to use a mean temperature to get meaningful results without needing to incorporate the full complexity (e.g. Costa et al. 2008; Lasaga and Jiang 1995). For systems with a protracted history of cooling or heating such as for metamorphic rocks, the concept of characteristic temperature was successfully demonstrated (Chakraborty 2006; Ganguly 2002). To illustrate the role of temperature we performed inverse diffusion models using two cases: one with the mean temperature of the two end-members $\left(1175^{\circ} \mathrm{C}\right)$, and another where we used the maximum Fo content recorded in the crystal as a proxy for the temperature. These are common approaches to approximate the relevant temperature of the process when studying natural crystals (e.g. Costa et al. 2008).

One consequence from the discussion above is that the forward times are typically shorter than the residence time due to the time delay of the crystals to begin to record the intrusion at their boundary (Figs. 1 and 2). Such an effect also applies to the calculated inverse times, and comparison of forward and inverse times provides a direct expression of the typical simplification employed when modeling crystals with constant temperature and boundary conditions when they have experienced many. We have found that inverse times can be longer or shorter than the forward times (Fig. 5), and that there is no major difference between the models that use the mean or the maximum Fo as a proxy for temperature (Fig. 5). The relative differences (Fig. 5) between the forward and inverse times show a positively skewed distribution when the residence time is $<40$ days, but they become a normal distribution with time (e.g., $>70$ days; Fig. 5). A broad conclusion from this analysis is that the inverse and forward times tend to overlap with increasing residence time, and that whether a mean temperature or the maximum Fo content is used as a proxy for temperature does not give very different results.

Another aspect that needs to be quantified is the relationship between the inverse time as could be derived from studies of natural crystals, and the residence time (Fig. 6). This gives an indication of the influence of the delay and the uncertainties on the temperature and composition history on the derived time from modeling the crystal zoning patterns. We find that for short residence times (e.g. 10 days) the inverse times are much shorter than the residence times, but as residence time increases to 70 and 100 days the inverse times are normally distributed, with a mean that is about 25\% lower than the residence time (Fig. 6). The exact values of these relationships are difficult to extrapolate to other conditions of time and diffusivity but give an idea of the general trends and dynamics of the system.

\section{Effect of zoning profile type on calculated times}

We also explored whether some types of zoning patterns better record the residence times than others. This is an indirect way to identify the effect of changes at the boundary with time, as the complexity of the zoning patterns is a record (although imperfect) of the variety of environments 
Fig. 5 Crystal-to-crystal comparison of the forward and inverse times for different residence times $(R=10,40,70$, and 100 days; marked with red vertical and horizontal lines in panels $\mathbf{a}, \mathbf{c}, \mathbf{e}, \mathbf{g})$. Inverse times were calculated using a mean temperature of $1175^{\circ} \mathrm{C}$ (symbols in blue), and the maximum Fo of each crystal as a proxy for temperature (symbols in orange). The times of all diffusion models are in general shorter than the residence time (e.g. symbols are inside the box defined by the residence time in panels $\mathbf{a}, \mathbf{c}, \mathbf{e}, \mathbf{g}$ ) because of the delay time (e.g. Figs. 1 and 2). Panels $\mathbf{b}, \mathbf{d}, \mathbf{f}$, and $\mathbf{h}$ show the relative error between the inverse and forward times using the two temperature models: I-F Error $(\%)=100 \times[$ (inverse time - forward time)/forward time]. See text for discussion
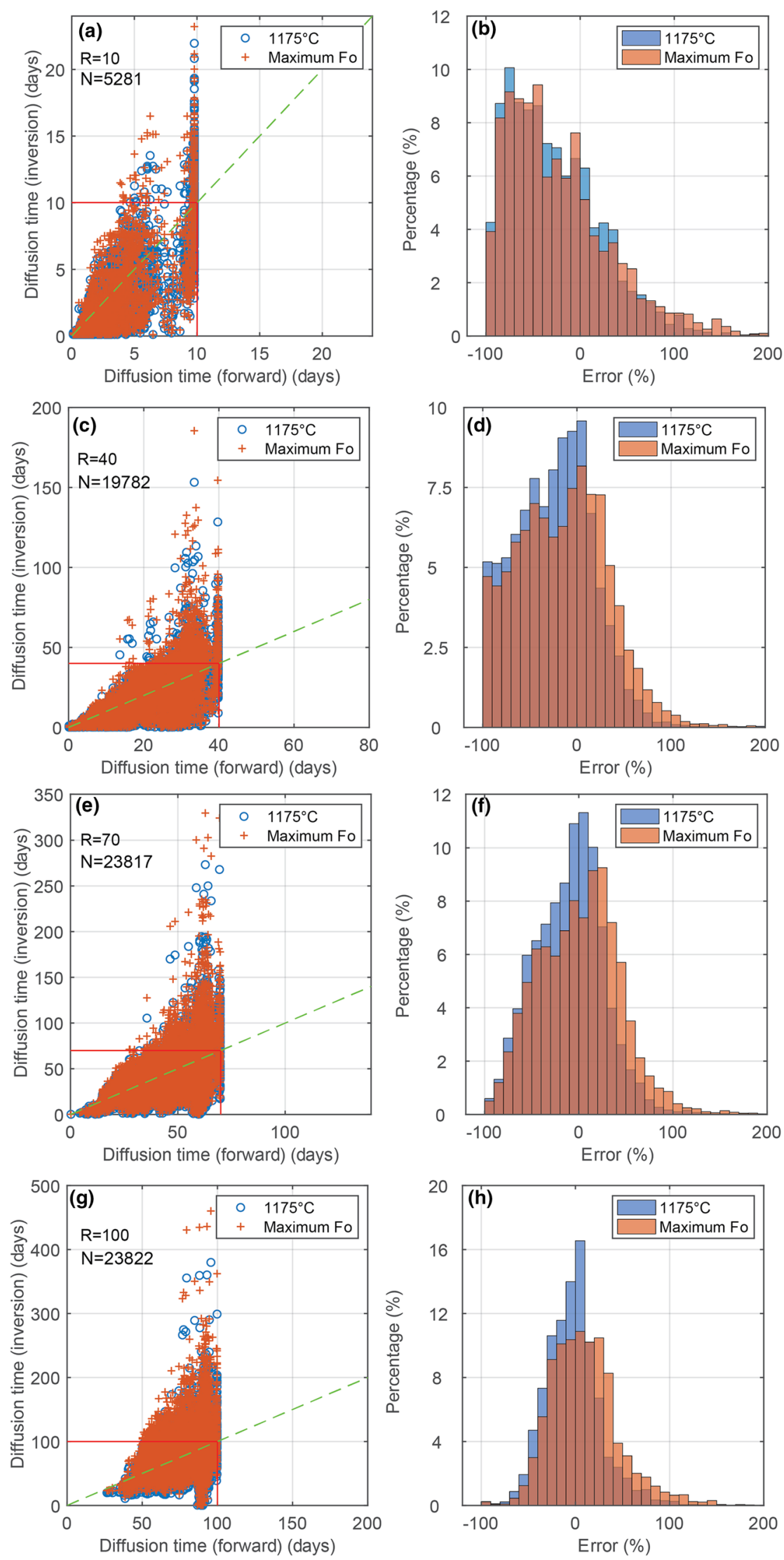


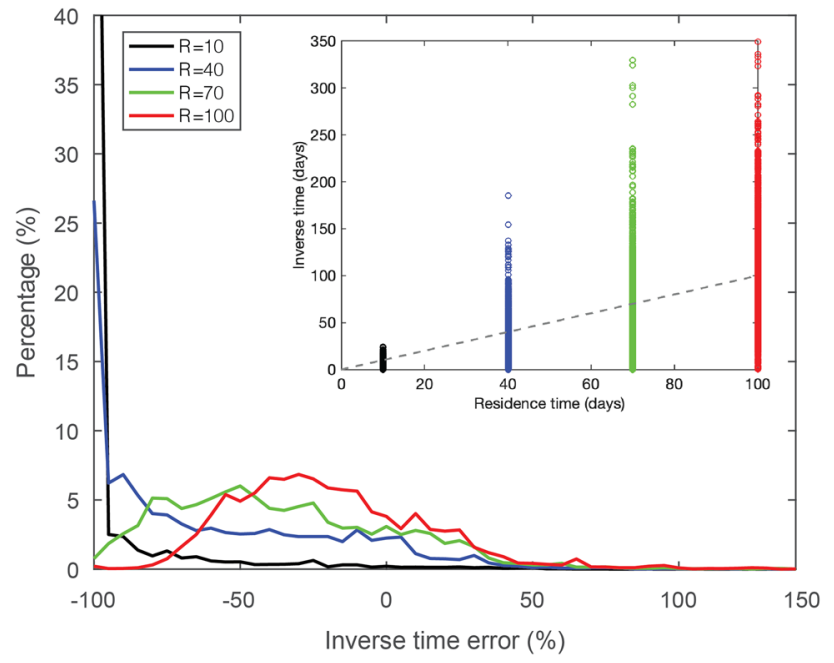

Fig. 6 Comparison of inverse times (here shown only those calculated with the temperature inferred from the maximum Fo) and residence times. Because of the delay and the changes of temperature and boundary composition that crystals are experiencing the inverses can be shorter or longer than the residence times (inset). This translates to relative errors of the inverse time $(=100 \times$ inverse time/ [inverse time - residence time]) that are very large for short residence time (e.g. black line for residence time of 10 days) but decrease and become more normally distributed with residence time (e.g. red line for residence time of 100 days)

the crystals have experienced. As noted above (Fig. 3) we found two types of zoning profiles, those that are simple and reverse in Fo, and those that are complex which show reverse followed by normal Fo zoning. We found that the crystals with complex zoning patterns give "mean" inverse and forward times that are in general closer to the residence time than those with reverse zoning profiles (Fig. 7). In addition, the mean inverse times of crystals with complex profiles, and using the maximum Fo as proxy for temperature give are the closest to the residence times (Fig. 7).

\section{Relationship between crystal zoning types, zoning length and times}

The proportions of the various crystal zoning patterns, the diffusion distance, and to some extent the variability of rim compositions are related, and systematically change with residence time (Fig. 8). With increasing residence time, the proportion of zoned crystals increases, and the proportion of simple reversed zoning dominates over the complex zoning. With increasing time, the length scale of the crystal zoning increases, and the variability of the rim compositions first increases and then stabilizes (Fig. 8). The exact values of the crystal proportions, diffusion lengths and other changes with time should vary from system to system, but their interrelationship can be used to better understand the processes and time scales obtained from modeling of olivine in natural

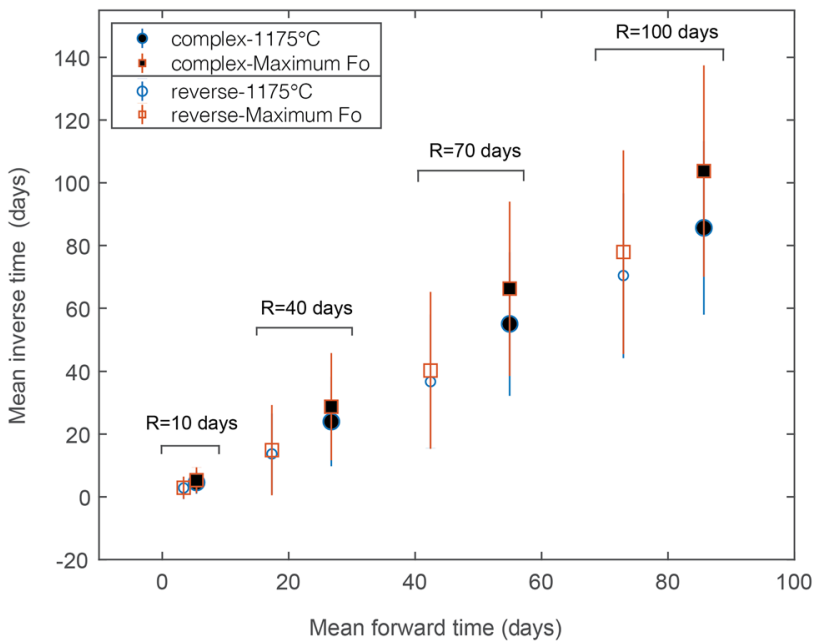

Fig. 7 The effect of the zoning profile style on the various diffusion times and comparison with the residence times $(R=10,40,70,100)$. The mean inverse time of reverse zoning patterns (circle) and complex zoning patterns (square) with $1 \sigma$ error are calculated with the mean temperature $\left(1175{ }^{\circ} \mathrm{C}\right)$, and using the maximum Fo observed as a proxy for temperature. The inverse diffusion time obtained from crystals with complex zoning are closer to the residence time than that of simple zoning crystals, with the models using the maximum Fo as proxy for temperature giving the closest to the residence time. For clarity the various times associated to a given residence time $(R=10,40,70,100)$ have been connected by a line

conditions. For example, characterization of the zoning patterns of large numbers of crystals including documentation of those that are not zoned, carries information about the time evolution of the system which can be combined with the time scales from modeling each profile at an individual level as is commonly done. These relationships can have a diagnostic role for determining whether a magma has been subject to multiple distinct intrusion events and the residence time.

\section{Estimating the number of crystals required to capture the distributions of calculated times}

A significant open question in geochemistry is the extent to which any given sample set is ergodic. That is, is the sample set 'complete' with respect to both the natural endmembers and the distributions between them. In the discussion above we have been using a very large number of crystals to characterize the different times and dynamics of the system, indeed all the available crystals. However, to be able to compare our results to natural systems it is important to consider the effect of the sample size on the distributions of inverse times (Fig. 9), as it is currently not the normal practice to study more than a few tens to a hundred crystals from natural systems. The shapes of the distributions of inverse times vary with residence time 
Fig. 8 Changes with time of several key parameters. a The percentage of crystals that are unzoned decrease with time, and the proportions of those with different zoning types change with time also. b Diffusion distance (i.e. length of the profile with a chemical gradient in micrometers ${ }^{2}$ ) of all zoned crystals increases with the residence time. c Standard deviation of Fo composition at the rim of 1000 crystals also varies with time. Although the exact values of the changes should vary with the details of each simulation scenario the observation that they are related could be used for internal consistency of data obtained from natural systems

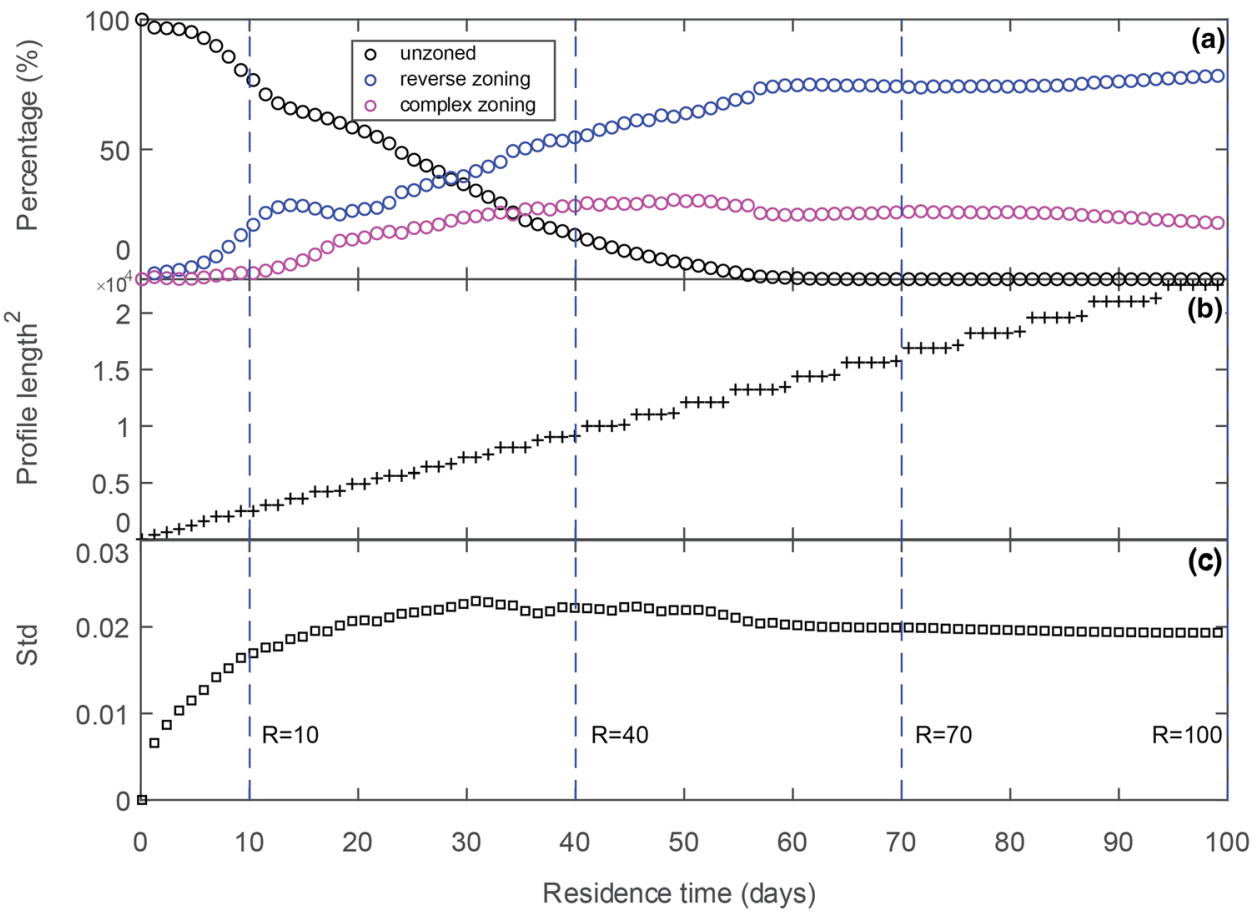

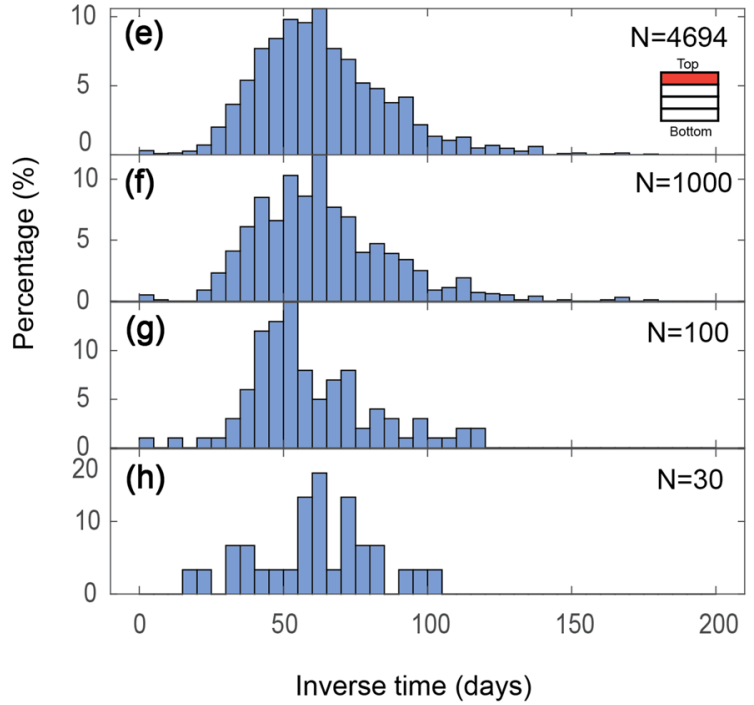

original distribution. Panels $\mathbf{e}$ to $\mathbf{h}$ show the distribution the inverse times of crystals from only the $25 \%$ upper part of the system (schematically noted in panel e. These have a narrower and better defined normal distribution and thus down-sampling to much smaller numbers of crystals (e.g. 30) still gives distributions that are close to the original one

distribution (Fig. 9). Although these are relatively high numbers of data to be obtained and profiles to model, they are not unrealistic, especially for the Fo zoning in olivine which can be calibrated with greyscale of electron backscattered images and a few quantitative analyses per 
section (e.g. Pankhurst et al. 2018). Similar numbers of crystals have been proposed to be necessary for considering of multidimensional effects on one dimensional profiles and random sampling of two dimensional sections to retrieve accurate time scale information (Shea et al. 2015).

\section{Discussion}

Our aim is to exemplify the controls on, and the complexity of, the crystal cargo in a highly simplified basalt reservoir containing a crystal mush, undergoing an open-system event. We did this by employing a multiphase numerical model of discrete element-fluid dynamics where the physical interactions are resolved at the crystal-scale. The temperature timeseries of every crystal was then subject to a diffusion model as a post-processing step. Hence the reaction progress itself was not incorporated in the physical model. This produces negligible error in the dynamics as the circulation and corresponding crystal response will not be much affected by small changes in liquid density or changes in crystal size or density. Our goals are to demonstrate the origins of fundamental features commonly observed in the crystal record, which can be expected in a wide variety of magmatic systems. This is a step-forward in illuminating how distinct populations arise, are dispersed, and the challenges in their interpretation.

Our approach of modeling the crystal response as diffusion is that it is more applicable to natural systems for which it can be shown that most of the zoning in the olivine is due diffusion, which is the case for quite a few studies (e.g. Albert et al. 2015; Kahl et al. 2017; Morgan et al. 2006; Ruth et al. 2018; Saunders et al. 2012). From the times we calculated, the inverse times are those that could apply to natural datasets where olivine zoning is the primary record of magma intrusion. Below we discuss how our results can be applied to better interpret the olivine record of eruptions sequences, and the relation to other observations that could be used to gather complementary information on volcanic processes and the residence time.

\section{Effect of the eruption on sampling of the plumbing system and crystal diffusion times}

The fluid dynamic simulations and crystal diffusion modeling show that even a very simple magma intrusion is likely to produce a heterogenous record in the crystals, with those at the closest to the newly intruding magma capturing more of the process (e.g. less delay times, Fig. 2). The proportions of the zoned crystals and the distributions of the calculated inverse times are also significantly different depending on the location of a crystal with regards to the intrusion (Fig. 10). The calculated inverse times for the different parts of the reservoir are

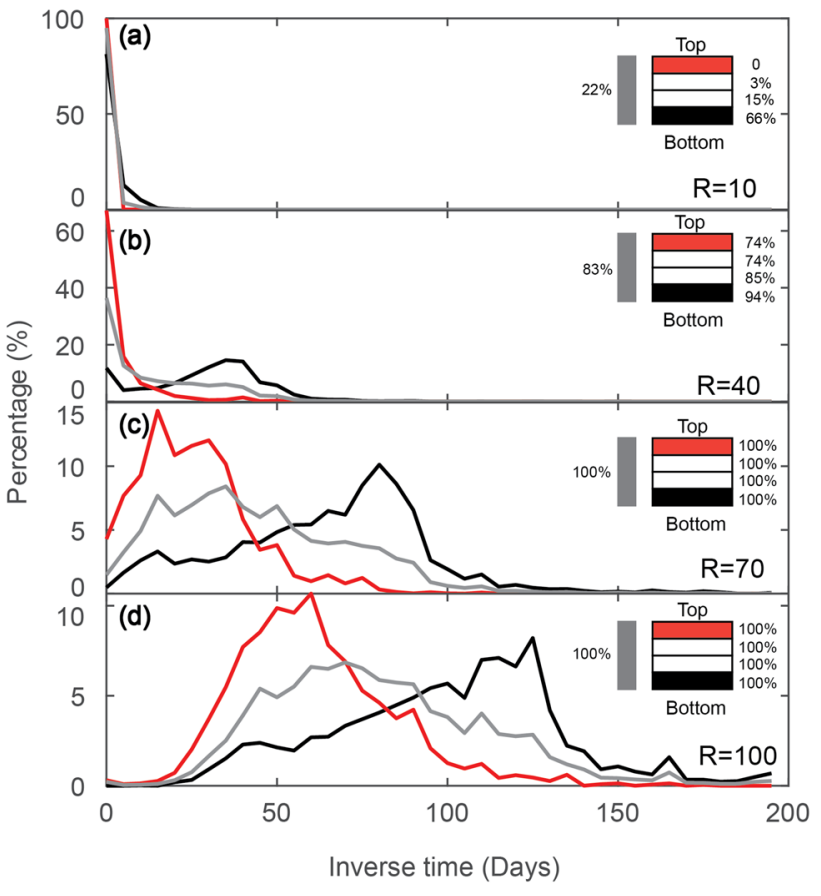

Fig. 10 Effect of initial crystal location in the mixing bowl on the calculated inverse times. The positions of the crystals in different parts of the bowl are schematically shown on the right upper corner of each panel. Red curves are crystals from the $25 \%$ upper part, crystals from the two middle areas are not shown to avoid cluttering of the figures, black curves are crystals from the $25 \%$ lowermost part, and grey curves are for all the crystals of the mixing bowl. The \% next to each layer correspond to the abundance of zoned crystals. Note that there is a systematic relationship between the crystal position and how inverse time change with residence time. Crystals from the bottom of the mixing bowl (black curve) give inverse times closer to residence time than those from the top (red curve). Such relationships could be used when studying natural systems that may have sampled the complete reservoir in an eruption sequence, and for which it can be shown that the crystal zoning is due to diffusion. Although the absolute values of the time difference from crystals of the different part of the mixing bowl depend on various parameters, the relative differences are likely still applicable

still between $25 \%$ (for crystals from the bottom part of the crystal pile) and $>50 \%$ (crystals from the top of the crystal pile) shorter than the residence time, but the systematic behavior of the crystal data as a function of location in the reservoir has the potential to be used to reveal the dynamics and configuration of the plumbing system. Although generic by nature, our findings might be especially applicable to short -lived and small volume mafic eruptions such as those from monogenetic volcanoes or dike fed events (e.g. Valentine and Gregg., 2008). Documenting of the changes in bulk-rock and crystal chemistry with eruption sequence (e.g. Brenna et al. 2010 and 2011; McGee et al. 2019) may reveal whether the eruption sequentially tapped the reservoir from top to bottom, whether magmas from a range of depths of the plumbing system where 


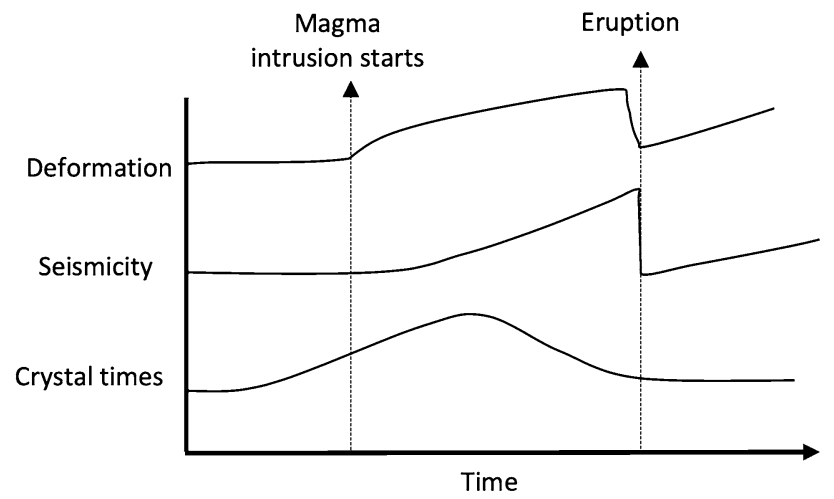

Fig. 11 Illustration of the relationship that can be expected between the times scales and signals of volcanic unrest such as deformation and seismicity with those obtained from model of crystals. Deformation and seismicity are adapted from Tilling (2008) and are from changes in tilt and numbers of short period earthquakes of PuuOo volcano in Hawaii one month between January-June 1986. Note that the mean of the crystal times is delayed with regards to the beginning of the magma intrusion as recorded in changes in deformation and seismicity

sampled at the same time, or whether multiple magmas from different sources intruded during the eruption (e.g. Brenna et al. 2011; Walowski et al. 2019). Depending on the duration of the magma intrusion and on the eruption itself one would expect that the crystal cargo would show progressively higher proportions of zoned crystals and of longer calculated inverse times.

\section{Implications for comparison of crystal time scales with time series of monitoring and observational dataset}

One of the objectives of this study was to illustrate and quantify, in the context of a simple example, the heterogeneity in the zoning record introduced during progressive open-system events. This delay decreases with residence time and recognition of this could be useful when trying to relate the intrusion times derived from olivine zoning with the changes in volcano monitoring parameters, such as deformation, seismicity, and gas composition (e.g. Albert et al. 2016; Kahl et al. 2011; Pankhurst et al. 2018; Ruth et al. 2018). The details of our result are however not intended to directly apply to a particular natural system, because the magnitude of the delay will depend on the geometry of the system, on whether crystals are from the most active region (like a mixing bowl), on the proportions of the resident and intruding magma, and on the duration of the intrusion itself. However, detailed comparison of the relationships between the onset and duration of seismic and deformation unrest with those of the inverse times
(Fig. 11) could be used to better understand the relationship between the processes in the plumbing system and those measured at the surface, especially if a sequence of eruption deposits can be sampled.

\section{Conclusions}

We combined the numerical results of discrete element-fluid dynamic simulations of magma mixing with the olivine zoning patterns that will be produced by a diffusion-only model. We find that the calculated inverse times from the modeling of crystals at a constant temperature and boundary composition are typically shorter (> about $25 \%$ ) than the residence times, although the value of the time differences depends on many variables, including the location of the crystal with respect to the intrusion, the total residence residence time, and the zoning style. Depending on the geometry of the system and the intrusion duration, there is a systematic relation between the crystal zoning proportions, lengths, and calculated inverse times, and the location of the crystals on the crystal pile (e.g. bottom vs top). Our approach is still a large simplification of the processes that may occur during magma crystal interactions, but they incorporate part of the complexity of changing temperature and melt composition at the crystal boundary, and explore the effects of down sampling of natural systems. Notwithstanding, our statistical analysis of the processes can be used to better understand the dynamics and plumbing system configuration of, for example, monogenetic volcanoes if crystal data exist for an eruption sequence. Our results can also be used to improve the conceptual models that relate the initiation and duration of magmatic intrusions from monitoring network data (seismic, deformation, gas) and those recorded by the crystal cargo.

Acknowledgements The reviews by T. Sheldrake, anonymous, and editor O. Müntener are appreciated and helped to largely clarify the content and discussion of the result of the paper. L.L.C. and F.C are supported by the National Research Foundation of Singapore and the Singapore Ministry of Education under the Research Centers of Excellence initiative, and a National Research Foundastion Singapore Investigatorship Award (NRF-NRFI2017-06). G.W.B. was supported by National Science Foundation grants DGE-1256068, EAR-1049884, EAR-1447266 and SI2-SSI-1549970.

Open Access This article is licensed under a Creative Commons Attribution 4.0 International License, which permits use, sharing, adaptation, distribution and reproduction in any medium or format, as long as you give appropriate credit to the original author(s) and the source, provide a link to the Creative Commons licence, and indicate if changes were made. The images or other third party material in this article are included in the article's Creative Commons licence, unless indicated otherwise in a credit line to the material. If material is not included in the article's Creative Commons licence and your intended use is not permitted by statutory regulation or exceeds the permitted use, you will need to obtain permission directly from the copyright holder. To view a copy of this licence, visit http://creativecommons.org/licenses/by/4.0/. 


\section{References}

Albert H, Costa F, Martí J (2015) Timing of magmatic processes and unrest associated with mafic historical monogenetic eruptions in tenerife island. J Petrol 56(10):1945-1966

Albert H, Costa F, Martí J (2016) Years to weeks of seismic unrest and magmatic intrusions precede monogenetic eruptions. Geology 44(3):211-214

Albert H, Costa F, Di Muro A, Herrin J, Métrich N, Deloule E (2019) Magma interactions, crystal mush formation, timescales, and unrest during caldera collapse and lateral eruption at ocean island basaltic volcanoes (Piton de la Fournaise, La Réunion). Earth Planet Sci Lett 515:187-199

Bergantz G, Schleicher J, Burgisser A (2015) Open-system dynamics and mixing in magma mushes. Nat Geosci 8(10):793

Bergantz GW, Schleicher JM, Burgisser A (2017) On the kinematics and dynamics of crystal-rich systems. J Geophys Res: Solid Earth 122(8):6131-6159

Brenna M, Cronin SJ, Németh K, Smith IEM, Sohn YK (2011) The influence of magma plumbing complexity on monogenetic eruptions. Jeju Island Korea: Terra Nova 23:70-75. https://doi.org/10 $.1111 / \mathrm{j} .1365-3121.2010 .00985 . x$

Brenna M, Cronin SJ, Smith IEM, Sohn YK, Németh K (2010) Mechanisms driving polymagmatic activity at a monogenetic volcano, Udo, Jeju Island, South Korea. Contrib Miner Petrol 160:931-950. https://doi.org/10.1007/s00410-010-0515-1

Carrara A, Burgisser A, Bergantz GW (2019) Lubrication effects on magmatic mush dynamics. J Volcanol Geoth Res 380:19-30

Chakraborty S (2006) Diffusion modeling as a tool for constraining timescales of evolution of metamorphic rocks. Mineral Petrol $88(1-2): 7-27$

Cheng L, Costa F, Carniel R (2017) Unraveling the presence of multiple plagioclase populations and identification of representative two-dimensional sections using a statistical and numerical approach. Am Miner 102(9):1894-1905

Costa F, Dungan M (2005) Short time scales of magmatic assimilation from diffusion modeling of multiple elements in olivine. Geology 33(10):837-840

Costa F, Morgan D (2011) Time constraints from chemical equilibration in magmatic crystals. Timescales of magmatic processes: from core to atmosphere. Wiley, Chichester, pp 125-159

Costa F, Dohmen R, Chakraborty S (2008) Time scales of magmatic processes from modeling the zoning patterns of crystals. Rev Mineral Geochem 69(1):545-594

Costa F, Coogan LA, Chakraborty S (2010) The time scales of magma mixing and mingling involving primitive melts and melt-mush interaction at mid-ocean ridges. Contrib Miner Petrol 159(3):371-387

Costa F, Shea T, Ubide T (2020) Diffusion chronometry and the timescales of magmatic processes. Nat Rev Earth Environ 1:201-214. https://doi.org/10.1038/s43017-020-0038-x

de Maisonneuve CB, Costa F, Huber C, Vonlanthen P, Bachmann O, Dungan MA (2016) How do olivines record magmatic events? Insights from major and trace element zoning. Contrib Miner Petrol 171(6):56

Dohmen R, Chakraborty S (2007a) Fe-Mg diffusion in olivine II: point defect chemistry, change of diffusion mechanisms and a model for calculation of diffusion coefficients in natural olivine. Phys Chem Miner 34(8):597-598

Dohmen R, Chakraborty S (2007b) Fe-Mg diffusion in olivine II: point defect chemistry, change of diffusion mechanisms and a model for calculation of diffusion coefficients in natural olivine. Phys Chem Miner 34(6):409-430

Estep J, Dufek J (2012) Substrate effects from force chain dynamics in dense granular flows. J Geophys Res: Earth Surface 117:F01028
Ganguly J (2002) Diffusion kinetics in minerals: principles and applications to tectono-metamorphic processes. Eur Miner Union 4:271-309

Ghiorso M, Sack R (1995) Chemical mass transfer in magmatic processes IV. A revised and internally consistent thermodynamic model for the interpolation and extrapolation of liquid-solid equilibria in magmatic systems at elevated temperatures and pressures. Contrib Mineral Petrol 119(2-3):197-212

Kahl M, Chakraborty S, Costa F, Pompilio M (2011) Dynamic plumbing system beneath volcanoes revealed by kinetic modeling, and the connection to monitoring data: an example from Mt Etna. Earth Planet Sci Lett 308(1-2):11-22

Kahl M, Chakraborty S, Pompilio M, Costa F (2015) Constraints on the nature and evolution of the magma plumbing system of Mt. Etna Volcano (1991-2008) from a combined thermodynamic and kinetic modelling of the compositional record of minerals. J Petrol 56(10):2025-2068

Kahl M, Viccaro M, Ubide T, Morgan DJ, Dingwell DB (2017) A branched magma feeder system during the 1669 eruption of $\mathrm{mt}$ etna: evidence from a time-integrated study of zoned olivine phenocryst populations. J Petrol 58(3):443-472

Kilgour G, Saunders K, Blundy J, Cashman K, Scott B, Miller C (2014) Timescales of magmatic processes at Ruapehu volcano from diffusion chronometry and their comparison to monitoring data. $\mathrm{J}$ Volcanol Geoth Res 288:62-75

Lasaga AC, Jiang J (1995) Thermal history of rocks; PTt paths for geospeedometry, petrologic data, and inverse theory techniques. Am J Sci 295(6):697-741

Lynn KJ, Garcia MO, Shea T, Costa F, Swanson DA (2017) Timescales of mixing and storage for Keanakāko'i Tephra magmas (1500-1820 C.E.), Kīlauea Volcano, Hawai ‘i. Contrib Mineral Petrol 172(9):76

Macdonald R, Belkin HE, Fitton JG, Rogers NW, Nejbert K, Tindle AG, Marshall AS (2008) The roles of fractional crystallization, magma mixing, crystal mush remobilization and volatile-melt interactions in the genesis of a young Basalt-Peralkaline Rhyolite suite, the greater Olkaria volcanic complex, Kenya rift valley. J Petrol 49(8):1515-1547

McGee L, Morgado E, Brahm R, Parada MÁ, Vinet N, Lara LE, Flores A, Turner M, Handley H, Nowell G (2019) Stratigraphically controlled sampling captures the onset of highly fluid-fluxed melting at San Jorge volcano, Southern Volcanic Zone Chile. Contrib Mineral Petrol 174(12):102

Morgan D, Blake S (2006) Magmatic residence times of zoned phenocrysts: introduction and application of the binary element diffusion modelling (BEDM) technique. Contrib Miner Petrol 151(1):58-70

Morgan D, Blake S, Rogers N, De Vivo B, Rolandi G, Davidson J (2006) Magma chamber recharge at Vesuvius in the century prior to the eruption of AD 79. Geology 34(10):845-848

Nakamura M (1995) Continuous mixing of crystal mush and replenished magma in the ongoing Unzen eruption. Geology 23(9):807-810

Pankhurst MJ, Morgan DJ, Thordarson T, Loughlin SC (2018) Magmatic crystal records in time, space, and process, causatively linked with volcanic unrest. Earth Planet Sci Lett 493:231-241

Philpotts AR, Brustman CM, Shi J, Carlson WD, Denison C (1999) Plagioclase-chain networks in slowly cooled basaltic magma. Am Miner 84:1819-1829

Probst LC, Sheldrake TE, Gander MJ, Wallace G, Simpson G, Caricchi L (2018) A cross correlation method for chemical profiles in minerals, with an application to zircons of the Kilgore Tuff (USA). Contrib Miner Petrol 173(3):23

Rae AS, Edmonds M, Maclennan J, Morgan D, Houghton B, Hartley ME, Sides I (2016) Time scales of magma transport and mixing at Kīlauea Volcano, Hawai'i. Geology 44(6):463-466 
Rasmussen DJ, Plank TA, Roman DC, Power JA, Bodnar RJ, Hauri EH (2018) When does eruption run-up begin? Multidisciplinary insight from the 1999 eruption of Shishaldin volcano. Earth Planet Sci Lett 486:1-14

Ruth DCS, Costa F, Bouvet de Maisonneuve C, Franco L, Cortés JA, Calder ES (2018) Crystal and melt inclusion timescales reveal the evolution of magma migration before eruption. Nat Commun 9(1):2657

Sandnes B, Flekkøy EG, Knudsen HA, Maløy KJ, See H (2011) Patterns and flow in frictional fluid dynamics. Nat Commun 2:288

Saunders K, Blundy J, Dohmen R, Cashman K (2012) Linking petrology and seismology at an active volcano. Science 336(6084): 1023-1027

Schleicher JM, Bergantz GW (2017) The mechanics and temporal evolution of an open-system magmatic intrusion into a crystal-rich magma. J Petrol 58(6):1059-1072

Schleicher JM, Bergantz GW, Breidenthal RE, Burgisser A (2016) Time scales of crystal mixing in magma mushes. Geophys Res Lett 43(4): 1543-1550

Shea T, Lynn KJ, Garcia MO (2015) Cracking the olivine zoning code: Distinguishing between crystal growth and diffusion. Geology 43(10):935-938

Sun Q, Jin F, Liu J, Zhang G (2010) Understanding force chains in dense granular materials. Int J Mod Phys B 24:5743-5759

Tilling RI (2008) The critical role of volcano monitoring in risk reduction. Adv Geosci 14:3-11. https://doi.org/10.5194/adgeo $-14-3-2008$
Tomiya A, Miyagi I, Saito G, Geshi N (2013) Short time scales of magma-mixing processes prior to the 2011 eruption of Shinmoedake volcano, Kirishima volcanic group. Japan Bulletin Volcanol 75(10):750

Turner S, Costa F (2007) Measuring timescales of magmatic evolution. Elements 3(4):267-272

Valentine GA, Gregg TKP (2008) Continental basaltic volcanoesprocesses and problems. J Volcanol Geoth Res 177(4):857-873

Wallace GS, Bergantz GW (2005) Reconciling heterogeneity in crystal zoning data: an application of shared characteristic diagrams at Chaos Crags, Lassen Volcanic Center, California. Contrib Mineral Petrol 149(1):98-112

Walowski KJ, Wallace PJ, Cashman KV, Marks JK, Clynne MA, Ruprecht $P$ (2019) Understanding melt evolution and eruption dynamics of the $1666 \mathrm{CE}$ eruption of Cinder Cone, Lassen Volcanic National Park, California: insights from olivine-hosted melt inclusions. J Volcano Geothermal Res 387:106665

Zhang Y (2008) Geochemical kinetics. Princeton University Press.

Publisher's Note Springer Nature remains neutral with regard to jurisdictional claims in published maps and institutional affiliations. 